\title{
Commentary on the article "Video-assisted preperitoneal repair of parastomal hernia" of Andrzej Jamry
}

\author{
Marek Szczepkowski \\ Clinical Department of General and Colorectal Surgery, Bielanski Hospital, Warsaw, Poland
}

Videosurgery and other miniinvasive techniques 2010; 5 (4): 129-131 DOI: 10.5114/wiitm.2010.18823

It was with great interest that I read the article titled "Video-assisted preperitoneal repair of parastomal hernia" published in Videosurgery and other miniinvasive techniques [1].

Since I am honoured to manage the Department of General Surgery in Bielanski Hospital, whose patients represent the largest group in Poland operated on due to parastomal hernias and one of the most widely described groups in the world literature, I took the liberty of commenting on the matter.

The author of the article describes a case of a 64-year-old female patient who has been operated on several times due to colonic carcinoma and its recurrence complicated by an internal fistula from the small bowel to the rectal stump. After the last surgery, a large, symptomatic, parastomal hernia occurred which deteriorated the condition of the patient's life considerably.

Painful sensations and difficulties connected with the supply of medical support equipment caused social isolation of the patient, who was, according to the author, otherwise in a relatively good state of health. Having taken into account carcinoma progression, past adjuvant therapy, increased risk for poor or delayed wound healing and expected peritoneal adhesions making laparoscopy contraindicated, the author decided to perform miniinvasive repair of the hernia. A polypropylene mesh (Surgipro), sized $12 \times 12 \mathrm{~cm}$, was placed within the preperitoneal cavity. Postoperative course was uncomplicated and hernia recurrence was not observed within 12 months following the procedure.
I congratulate the author on the success, but still I have a few remarks to make.

There are three fundamental methods available for hernia surgical repair: relocation of stoma, procedures using autologous tissue, and procedures using synthetic materials. As they are associated with a high recurrence rate, even up to $100 \%$, the first two cannot be treated as methods of choice [2-10] and therefore they are inadvisable to be performed electively. Their application appears to be limited to emergent surgical situations, particularly if intraoperative, massive infection of the operative field occurs, caused by necrosis, intestine perforation or resection.

Potential contamination of prosthetic material and possible following complications necessitating surgical removal of a mesh present a much greater threat than the recurrence itself.

The recurrence rate was substantially reduced by the use of synthetic materials [11]. However, none of the methods available can be recommended as the standard approach. The suggested techniques differ from each other in many fundamental ways. There is no unified way of access - open hernia repairs, laparotomic and laparoscopic surgery are all recommended. Various prosthetic materials are used. The most common is polypropylene, the second most popular is PTFE (polytetrafluoroethylene), then composite mesh, finally poly(vinylidene fluoride) (PVDF) and acellular dermal matrix (ADM), which has been introduced only recently into clinical practice and raises hope of broadening the scope of its application. Further differences are connected with the 
approach to mesh placement in the anatomical space. In the open approach and laparotomic surgery, the prosthesis is most typically placed either on the fascia (onlay technique) or in the preperitoneal cavity. During laparoscopic access a mesh is placed in the peritoneal cavity, which excludes using a polypropylene prosthesis. It cannot be left in direct contact with the bowels due to the strong possibility of adhesions and fistulas. It should be noted here that the price of meshes frequently exceeds the financial capabilities of Diagnosis Related Groups.

So many differences consequently have led to the creation of varied methods, which are often described with reference to a small number of patients or presented as case reports.

This makes assessment of each particular method difficult, especially with lack of homogeneity of series compared. The limited evaluation research and short observation time make the appraisal based on the recurrence rate somewhat unconvincing. The review of surgical techniques for parastomal hernia repair shows that the authors focus exclusively on closure of a hernial ring, neglecting concomitant complications. Few authors see parastomal hernia repair in a wider context, taking into consideration creation of a functional stoma and improvement in patients' quality of life [12].

Having chosen what seemed to be the best solution, the author of the article under discussion placed the mesh in the preperitoneal cavity. However, preparation of this space is one of the most important and difficult stages of the procedure, especially in cases of recurrent and extensive hernias due to adhesions and bleeding occurring there.

The technique I use opens the preperitoneal space with a circumferential incision of the fascia, made around the hernial ring, about $0.5 \mathrm{~cm}$ from its edge. Such a cut, made quite precisely, usually allows for preparation in the area where the anterior abdominal wall is still a layered structure. This significantly facilitates access to the correct area and causes the least possible enlargement of the existing hernial defect. I follow the rule of leaving $5 \mathrm{~cm}$ of the defect as a minimum (preferably $8-10 \mathrm{~cm}$ ). Preparation is usually begun from the median side, where the cavity behind the rectus abdominis muscle is opened between its posterior surface and the anterior wall of the posterior lamella of the rectus muscle when preparing above the arcuate line. When preparing below the arcuate line, the cavity is opened between the posterior surface of the rectus abdominis muscle and the transverse fascia of the abdomen. The medial border of the area mobilized is usually defined by a scar resulting from a primary median incision, which did not take place in the case discussed. Inferolateral preparation can be easily performed and blunt dissection is used to separate the peritoneum together with the surrounding fatty tissue from the fascia. For superolateral preparation, sharp dissection is usually necessary to create an area homogeneous with the previously opened space behind the rectus abdominis muscle. To accomplish this it is necessary to make an upward incision of the lateral edge of the sheath of the rectus abdominis muscle. The incision must be long enough to form an expected margin of hernia defect and to divide the area between the lateral muscle and internal oblique muscle. This stage of the procedure requires very careful homeostasis. The created space extends frontally between the posterior surface of the rectus abdominis muscle and the posterior surface of the internal oblique muscle and the anterior surface of the posterior lamella of the rectus abdominis muscle sheath and anterior surface of the lateral muscle above the arcuate line, and below it to the front from the peritoneum covered with fatty tissue and transverse fascia. This description implies how complicated preparation of the preperitoneal cavity may be. Its formation by means of the established emphysema may not be enough, or sometimes simply impossible. The case described by the author was successful my congratulations. It is necessary to emphasize though that the goal of surgical hernia treatment is to eliminate the hernia ring, in other words to reduce the diameter of the stomal canal and to remove excess peritoneum creating the hernial sac (only in the case of a small hernia is it not required).

Leaving a big hernial sac may result in formation of seromas, which gives the patient an elevated risk of developing additional complications.

The stoma ring is narrowed by creating an opening in the mesh, supplemented with a monofilament suture, which is referred to as the "calibrating suture" $[13,14]$, and the recreation of the muscle layer and fascia barrier above it.

Those manoeuvres could not have been performed by the author for the apparent reasons. It should be stated here that there are meshes dedicated to parastomal hernia. They have a special opening for the stomal canal and a specially constructed col- 
lar of different sizes. However, due to high costs (they are not refunded by the National Health Fund), they cannot be used routinely in Poland.

Besides the comments above, I have a few more practical remarks concerning the use of a mesh. In the case of the majority of parastomal hernias a mesh of size $12 \times 12 \mathrm{~cm}$, such as was used by the author, is too small. We usually use meshes of size $400-500 \mathrm{~cm}^{2}$, but it is connected, of course, with the size of the hernia and the quality of tissues of the anterior wall of the abdomen. The use of too small a mesh is related to the risk of hernia development outside the synthetic material. It is also necessary to remember about the effect of "mesh contraction". The author aptly writes about the advantages of miniinvasive technique in cases of parastomal hernias [1]. I am a great supporter myself of wider application of laparoscopy in common surgical practice, and also in advanced techniques (e.g. large bowel surgery). However, laparoscopy has major limitations in the case of parastomal hernias. The decision whether to choose open or laparoscopic technique for parastomal hernias depends on a great number of aspects, some of the most important being:

- the size of the hernia (especially the size of the hernia sac and the necessity of its complete resection),

- extensive interintestinal adhesions and adhesions between the intestine and peritoneum of the hernia sac,

- deformation of the anterior wall of the abdomen, which is an indication for plastic surgery of the abdominal wall, not in every case of course,

- other locally existing stoma complications (narrowing, falling out), which can be cured simultaneously,

- patient's expectations,

- cost of the mesh.

Safety problems of mesh application when used during the primary intestinal stoma operation to prevent parastomal hernia occurrence are crucial and are not completely solved, but this topic is not of relevance to my commentary. It is a pity that the author while discussing the topic did not refer to Polish papers $[13,15]$ concerning the matter.

To sum up, I would very much like to congratulate the author on the success of the procedure and ask him to accept these few friendly remarks, which were made out of concern for the best quality of treatment and life of patients after difficult operations of parastomal hernia repair.

\section{References}

1. Jamry A. Video-assisted preperitoneal repair of parastomal hernia. Videosurgery and other miniinvasive techniques 2009; 4: 79-82.

2. Prian GW, Sawyer RB, Sawyer KC. Repair of peristomal colostomy hernias. Am J Surg 1975; 130: 694-6.

3. Williams JG, Etherington R, Hayward MW, Hughes LE. Paraileostomy hernia: a clinical and radiological study. Br J Surg 1990; 77: 1355-7.

4. Rubin MS, Schoetz DJ Jr, Matthews JB. Parastomal hernia. Is stomal relocation superior to fascial repair? Arch Surg 1994; 129: 413-8; discussion 418-9.

5. Taylor RL Jr, Rombeau JL, Turnbull RB Jr. Transperitoneal relocation of the ileal stoma without formal laparotomy. Surg Gynecol Obstet 1978; 146: 953-8.

6. Stephenson BM, Phillips RKS. Parastomal hernia: local resiting and mesh repair. Br J Surg 1995 Oct; 82(10): 1395-6.

7. Botet X, Boldo E, Llaurado JM. Colonic parastomal hernia repair by translocation without formal laparotomy. Br J Surg 1996; 83: 981.

8. Cheung MT, Chia NH, Chiu WY. Surgical treatment of parastomal hernia complicating sigmoid colostomies. Dis Colon Rectum 2001; 44: 266-70.

9. Allen-Mersh TG, Thomson JP. Surgical treatment of colostomy complications. Br J Surg 1988; 75: 416-8.

10. Horgan K, Hughes LE. Para-ileostomy hernia: failure of a local repair technique. Br J Surg 1986; 73: 439-40.

11. Carne PWG, Robertson GM, Frizelle FA. Parastomal hernia. Br J Surg 2003; 90: 784-93.

12. Evans JP, Brown MH, Wilkes GH, et al. Revising the troublesome stoma: combined abdominal wall recontouring and revision of stomas. Dis Colon Rectum 2003; 46: 122-6.

13. Szczepkowski M, Gil G. Przedziurawienie okrężnicy przez siatkę syntetyczną po operacjach przepuklin okołostomijnych: późne powikłanie skutecznie leczone naprawą miejscową bez przemieszczania stomii lub usunięcia siatki. Proktologia 2008; 9: 217-23.

14. Szczepkowski M, Gil G. Operacja naprawy dużej przepukliny okołostomijnej z użyciem materiału syntetycznego. Chirurgia po Dyplomie 2010; 5: 68-81.

15. Gil G, Szczepkowski M, Ciesielski P. Naprawa przepuklin okołostomijnych z użyciem siatek syntetycznych - ocena wczesnych wyników. Pol Przeg Chir 2005; 77: 254-63. 